\title{
An Empirical Study on Customers' Satisfaction of Third-Party Logistics Services (3PLS)
}

\author{
YU LIU \\ International Business School, Shan Xi Normal University, China \\ Xi An City, China \\ Email:191017804@qq.com
}

\begin{abstract}
With the rapid growth of third-party logistics (3PL) in the global logistics industry, it is important to gain further insight into customers' satisfaction of third-party logistics services (3PLS). This study proposes a conceptual model that delineates the determinants of consumers' perceived service quality, as well as the effects of perceived service quality and customer expectation on customers' satisfaction for third-party logistics services (3PLS). To test the model, structural equation modeling is employed to analyze data collected from 152 respondents in Chinese logistics companies. This research provides a theoretical foundation for academics and also practical guidelines for logistics service providers in dealing with third-party logistics service aspects.
\end{abstract}

Key Words---Third-party Logistics service (3PLS), Perceived Service quality, Customer expectation, Customer satisfaction

\section{INTRODUCTION}

\section{A. Research Background and Purpose}

Over the last two decades, the 3PLs $\left[{ }^{1}\right]$ providers have become important Payers in many chains and industries. According to Outsourcing Logistics Report 2006), over 60 percent of Fortune 500 firms have at least one contract with a 3PL service provider. $\left[{ }^{2}\right]$ Once the decision has been made to work with a 3PLs provider, the next decision is to determine which provider. Thus, the selection of an efficient and potential set of 3PLs providers who can meet the service requirements of the customer and with whom the customer can strengthen its relationships become a crucial decision.

During the past decade, Parasuraman, Zeithaml, and Berry (1985a, b) have revealed that regardless of the type of service, consumers used basically similar criteria in evaluating service quality. $\left[{ }^{3}\right]$ After empirical investigation and analysis, Parasuraman, Zeithaml, and Berry (1988) have proposed the revised five -aspect representation of service quality: Tangibles, Reliability, Responsiveness, Assurance and Empathy.[ $\left.{ }^{4}\right]$ Later, Kim, Cheong, and Cho (2006) $\left[{ }^{5}\right]$ and Tsaur, Chang and Yen (2001) $\left[{ }^{6}\right]$ applied them in practice. However, despite the wide spread of SERVQUAL, empirical research that uses this scale in the 3PL services context is very scarce.

On the other hand, since 1970s, researchers of consumer behavior and marketing in developed countries have begun to make comprehensive studies on customer. This research use China as the site of empirical investigation. In the last decades, in China lots of causal models were constructed to indicate the relationships among perceived performance, customer satisfaction and loyalty. Combined other scholars' results and industry conditions, a customer satisfaction conceptual model for Chinese logistics enterprises $\left[{ }^{7}\right]$ is proposed. But among these research results, few of them took industry factors into account. There is no practical suggestion for logistics enterprises to evaluate and improve customer satisfaction either.

Based on above, the research purpose of this study is stated below: Firstly, the study states some related theories about service quality of 3PL and customers' satisfaction. Secondly, the study proposes and tests the research conceptual model of customers' satisfaction of 3PL service. Finally, the study concludes with a discussion and future directions for research.

B. Research Methodologies

Measurement assessments are used to validate our model. Following recommendations of prior studies for developing and validating measurement instruments $\left[{ }^{8}\right]$, our study conducts a three-stage procedure. The first stage is conducted through a review of the relevant literature and corresponding scales. $\left[{ }^{9}\right]$ In stage two, a set of sample items is generated for each construct and assessed for the reliability and content validity $\left[{ }^{10}\right]$. In stage three, we proceed with an extensive confirmatory analysis for Chinese third-party logistics service of CSI by testing and validating the refined scales for the reliability and construct validity. We also verify convergent validity and the goodness-of-fit of our research model.

\section{RESEARCH MODEL AND HYPOTHESES}

A. Research Model

In the model, we attempted to use the five dimensions 
(Tangibles, Reliability, Responsiveness, Assurance, and Empathy) to measure the perceived service quality of 3PL service providers. This study attempts to propose and test a research conceptual model of Chinese logistics customer satisfaction which adopts both its perceived service quality and customer expectation as affecting factors. Therefore Customers' Satisfaction Model for Third-party logistics service (Figure 1) is proposed as the followings:

\section{B. Hypotheses}

\section{1) Evaluation Criteria for 3PL Service Quality}

According above, evaluation criteria for 3PL service quality include five generic dimensions such as tangibles, reliability, responsiveness, assurance, and empathy.

a) Tangibility means the physical evidence of the service presentation such as logistics physical facilities, logistics tool or equipment used to provide the service, appearance of logistics personnel ,and so on;

a) Reliability stands for the how credible the logistics service providers is in terms of consistency of performance and dependability. It means that the firm performs the service right the first time.

c) Responsiveness aspect describes how logistics personnel interact with customers. It concerns the willingness or readiness of employees to provide service. It involves timeliness of service: mailing a transaction slip immediately; calling the customer back quickly; and giving prompt service (e.g., setting up appointments quickly

d) Assurance aspect represents the certainty that logistics service provides for customers.

e) empathy aspect represents how logistics service provides deal with the customer complaints and provides thoughtful services.

Therefore, the following hypotheses were tested:

Hypothesis 1: Tangibility is positive associated with perceived service quality.

Hypothesis 2: Reliability is positive associated with perceived service quality.

Hypothesis 3: Responsiveness is positive associated with perceived service quality.

Hypothesis 4: Assurance is positive associated with perceived service quality.

Hypothesis 5: Empathy is positive associated with perceived service quality.

\section{2) Customer expectations}

Expectations are viewed as predictions made by consumers about what is likely to happen during an impending transaction or exchange. Customer expectation as a pivot exogenous latent variable has different influences to other constructs in CSI models. This influence is largely determined by the categories the measured products or services belong to. The third party logistics enterprises should pay attention to the relationship between customer expectations, perceived quality and consumer satisfaction. Thus, search of customer expectation will be crucial to build a more precise and comparable CSI model. Based on this observation, the following hypothesizes are proposed.

Hypothesis 6: Customer expectation is positive associated with perceived service quality.

Hypothesis 7: Customer expectation is positive associated with consumer satisfaction.

\section{3) Perceived service quality.}

It is the customer's perception of what actually did, should or will occur. Service quality comes from service strategy, service system and service personnel. Based on insights from the present study, perceived service quality is further posited to exist along a continuum ranging from ideal quality to totally unacceptable quality, with some point along the continuum representing satisfactory quality. The position of a consumer's perception of service quality on the continuum depends on the nature of the discrepancy between the expected service (ES) and perceived service (PS).When ES $>$ PS ,Perceived quality is less than satisfactory; When ES=PS, perceived quality is satisfactory; when $\mathrm{ES}<\mathrm{PS}$, perceived quality is more than satisfactory. Therefore, the hypotheses are suggested as shown below:

Hypothesis 8 Perceived service quality is associated with consumer satisfaction.

\section{Measurements of Research Variables}

This section describes the measurement of the five principal variables that affect customers' satisfaction of third-party logistics service. 
$<$ Table-1> Measurements of Research Variables

\begin{tabular}{|c|c|}
\hline Variables & Measurements \\
\hline Tangibility & $\begin{array}{l}\text { 1.Ensure physical facilities } \\
\text { 2.Ensure tools or equipment used to provide } \\
\text { the service } \\
\text { 3.Ensure appearance of personnel }\end{array}$ \\
\hline Reliability & $\begin{array}{l}\text { 1.Ensure professional skill of personnel } \\
\text { 2.Ensure Timeliness } \\
\text { 3.Ensure safety }\end{array}$ \\
\hline Responsiveness & $\begin{array}{l}\text { 1. Ensure mailing a transaction slip } \\
\text { immediately } \\
\text { 2. Ensure calling the customer back quickly } \\
3 \text { Ensure setting up appointments quickly }\end{array}$ \\
\hline Assurance & $\begin{array}{l}\text { 1. Ensure actively providing service } \\
\text { 2. Ensure competitive competence }\end{array}$ \\
\hline Empathy & $\begin{array}{l}\text { 1.Ensure leaning the customer's specific } \\
\text { requirement } \\
\text { 2.Ensure providing individualized attention } \\
3 \text { Ensure customer complaints handing }\end{array}$ \\
\hline $\begin{array}{c}\text { Perceived } \\
\text { service quality }\end{array}$ & $\begin{array}{l}1 \text { Degree of the customer actually perceived } \\
\text { 2.Degree of the customer should perceive } \\
3 \text { Degree of the customer will perceive }\end{array}$ \\
\hline $\begin{array}{l}\text { Consumer } \\
\text { expectation }\end{array}$ & $\begin{array}{l}\text { 1.Consider the ideal expectation } \\
\text { 2.Consider the desirable expectation } \\
\text { 3.Consider the minimum tolerable } \\
\text { expectation }\end{array}$ \\
\hline $\begin{array}{l}\text { Consumer } \\
\text { satisfaction }\end{array}$ & $\begin{array}{l}\text { 1. Degree of transaction satisfaction from } \\
\text { good to bad. } \\
\text { 2.Degree of transaction satisfaction from } \\
\text { harmful to beneficial }\end{array}$ \\
\hline
\end{tabular}

\section{EMPIRICAL ANALYSIS AND RESULTS}

\section{A. Data Collection}

This research uses China as the site of the empirical investigation. The reason is that we have found third-party logistics service market to be more active and potential in China, compared to other countries: hence, China is an appropriate site for our study on customers' satisfaction of third-party logistics service.

The survey respondents for this study were recruited from December 2013 to May 2014 and the participants were solicited through distributing questionnaire by email. Each questionnaire was defined with composing of a five-point
Likert-scales where ' 1 = strongly disagree', ' 2 = disagree', ' 3 = neutral', ' 4 =agree' and ' $5=$ strongly agree'. Altogether, 168 questionnaires were collected by personal visits and email. 18 questionnaires were eliminated due to invalid answers, leaving 152 questionnaires for our empirical analysis (a response rate of 15.2\%).

\section{B. Reliability and Validity Tests}

\section{1) Reliability Test}

As shown in results, the reliability scores of all the constructs were found to exceed the threshold set by Nunnally; all measures demonstrated good levels of reliability (greater than 0.60 ).

\section{2) Validity Test}

SPSS (Statistical Package for the Social Sciences) software was used in the assessment of validity.

We concluded that the data were approximately multivariate normal data. Furthermore, the correlation matrix contained sufficient covariation for factoring. To determine that tangibility, reliability, responsiveness, assurance, empathy, perceived quality, customer expectation and customer satisfaction are separate variables; a confirmatory factor analysis was conducted through SPSS.

\section{Structural Equation Modeling}

The correctness of the research model was tested by using structural equation modeling techniques with AMOS 6.0. The Chi-square statistic of the model was 378.065 with 198 of freedom, thus indicating a good fit with the model (a ratio of less than 3). However, since the Chi-square test is very sensitive to the sample size, we employed a number of other indices to further test the model fit. All the indices RMR and RMSEA - are at acceptable levels. Overall, the results showed that our model provides a valid framework for the measurement of customer satisfaction for Chinese third party logistics enterprises (3PLE).

\section{Hypotheses-path testing}

This section presents the statistical results of the measurement validation and hypothesis testing. The effects of tangibility, reliability, responsiveness, assurance and empathy on customer satisfaction in 3PLE were assessed through AMOS 6.0. Our empirical results are shown in 
Table 2.

<Table-2> Path Coefficients and Regression Weights

\begin{tabular}{|l|c|c|c|c|}
\hline \multicolumn{1}{|c|}{ Relations } & Estimate & S.E. & C.R. & P-Value \\
\hline $\begin{array}{l}\text { Perceived Service Quality } \\
\text { <---Tangibility }\end{array}$ & .412 & .099 & 4.181 & $* * *$ \\
\hline $\begin{array}{l}\text { Perceived Service Quality } \\
\text { <---Reliability }\end{array}$ & .090 & .050 & 1.792 & $.073^{*}$ \\
\hline $\begin{array}{l}\text { Perceived Service } \\
\text { Quality<---Responsiveness }\end{array}$ & .330 & .061 & 5.457 & $* * *$ \\
\hline $\begin{array}{l}\text { Perceived Service Quality } \\
\text { <--- Assurance }\end{array}$ & .398 & .070 & 5.689 & $* * *$ \\
\hline $\begin{array}{l}\text { Perceived Service Quality } \\
<--- \text { Empathy }\end{array}$ & -.151 & .128 & -1.177 & .239 \\
\hline $\begin{array}{l}\text { Perceived Service Quality } \\
\text { <---Consumer Expectation }\end{array}$ & .583 & .164 & 3.552 & $* * *$ \\
\hline $\begin{array}{l}\text { Consumer } \\
\text { Satisfaction<---Customer } \\
\text { Expectation }\end{array}$ & -.309 & .127 & -2.432 & $.015 * *$ \\
\hline $\begin{array}{l}\text { Consumer } \\
\text { Satisfaction<---Perceived } \\
\text { Service Quality }\end{array}$ & .572 & .119 & 4.805 & $* * *$ \\
\hline \multicolumn{1}{|c|}{$* 0.1 ; \mathrm{P}<0.05 ;$} \\
\hline
\end{tabular}

As shown in Table 2, the effects of tangibility, reliability, responsiveness and assurance on consumers' perceived service quality in Chinese 3PLE were significant $\left(\beta_{\text {tag }}=0.412, \mathrm{p}<0.01 ; \beta_{\text {rel }}=0.090, \mathrm{p}<0.1, \beta_{\text {res }}=0.330, \mathrm{p}<0.01\right.$; and $\left.\beta_{\text {ass }}=0.398, \mathrm{p}<0.01\right)$. Hence, Hypothesis 1 (H1), 2 (H2), 3 (H3) and Hypothesis 4 (H4) are strongly supported by the results. In contrast, the effect of empathy on consumers' perceived service quality in Chinese 3PLE was not significant $\left(\beta_{\mathrm{emp}}=-0.151, \mathrm{p}=0.239\right)$, showing that empathy does not act as an antecedent of consumers' perceived service quality in Chinese 3PLE. Hence, Hypothesis 5(H5) is not supported.

Our result shows that customer expectation in 3PLE exerts a substantial effect on customer perceived service quality $\left(\left(\beta_{\text {con }}=0.583, \mathrm{p}<0.01\right)\right.$, thus validating Hypothesis 6 (H6). Finally, our results also indicate that perceived service quality $\left(\beta_{\mathrm{per}}=0.572, \mathrm{p}<0.01\right)$ and customer expectation ( $\left.\beta_{\text {cus }}=-0.309, \mathrm{p}<0.05\right)$ are strongly associated with customer satisfaction in Chinese 3PLE. Thus, Hypothesis 7 (H7) and Hypothesis 8(H8) are supported.

Overall, the path coefficients of $\mathrm{H} 1, \mathrm{H} 4, \mathrm{H} 3, \mathrm{H} 6$, and H7 were significant at a level of $\mathrm{p}<0.01$, thereby indicating support for these hypotheses. The path coefficient of $\mathrm{H} 2$ and $\mathrm{H} 8$ were significant at a level of $\mathrm{p}<0.1$ and $\mathrm{p}<0.05$, thus indicating support for the second and eighth hypotheses. Hypothesis 5 is not supported. Fig. 2 shows a summary of our results for each hypothesis in the research model. The significance of the estimates is indicated by a solid line.

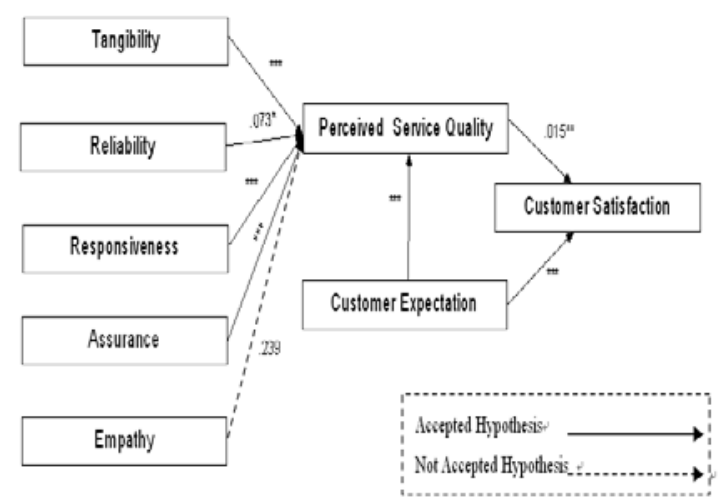

Figure 2 Output path diagram of the research model

\section{CONCLUSIONS AND IMPLICATIONS}

This study provides important theoretical and practical contributions to the area of 3PL service. This research develops a theoretical model of customers' satisfaction of 3PL service. It helps to explain the direct relationships between perceived service quality, customer expectation, and customers' satisfaction in 3PL service. Our results clearly delineate the role of Customers' perceived service in building customers' expectation and the positive impact of both perceived service quality and customers expectation on 3PL use. The effects of five determinants of 3PL service quality on consumers' perceived quality are also validated. Customers' perceived quality and customer expectation are essential concepts in our understanding of customers' use of 3PLS. This research is consistent with previous claims that both perceived service and customer expectation perform a crucial function in promoting customers' use of 3PLS. By presenting an empirically devised set of customers' satisfaction issues in 3PLS, this research can serve as a basis for the selection of appropriate indicators for further empirical research.

This study suggests that mere introduction of 3PL services is not going to be sufficient to attract users to choose 3PL service providers. 3PL service providers should reinforce the physical concerns of customers and promote customers' belief in the trustworthiness of services. Some service providers merely concentrate on the physical concerns and ignore the importance of customers' belief in 3PL service use. Others hold the notion of "more is better" or "as detailed as possible" on procedural design, based on the objective dimension of consideration, which seems to be reasonable in terms of obtaining customers' confidence in 3PLS. However, from the subjective viewpoint of consumers, this practice ignores the ease of use in operation 
and thus, can be counterproductive. It is of prime importance for 3PLS to develop customers' satisfaction that are deemed as consideration on both objective and subjective levels. Thus, management needs to focus on the promotion of these considerations among customers when improving service systems.

This study is not free from limitations. The first, although the research comes up with some significant findings from the viewpoint of customers, it does not include all the factors that affect consumers' satisfaction of 3PLS. For example, factors, such as social and individual factors can be taken into consideration in future research. Also special attention should also be paid to human factors, management, education, awareness, and other non-technology factors. The second, all the participants in the samples in our research had experience in 3PLS use. Pre-interaction factors, such as brand reputation, advice, or experience from trusted sources of information (e.g. word of mouth and traditional media), were not considered in our research model. It would be interesting for further research to focus on other factors that give more detailed information on customers' satisfaction in 3PLS. The third, the sample employed for our empirical analysis was collected from logistics service users in China. The issues associated with 3PLS are widely recognized in countries with more advanced developing stage. Thus, it would be interesting to compare the results of this study to those of studies that are conducted through samples collected from other countries.
Considering these limitations, our research constitutes an important stepping-stone for future research in different national settings in which it involves an investigation of the factors that influence customers' satisfaction of 3PLS.

\section{REFERENCES}

[1] Leahy, S.E., Murphy, P.R., Poist, R.F., 1995. Determinants of successful logistical relationships: A third-party provider perspective. Transportation Journal 35(2), 5-13

[2] Eye for transport. Outsourcing Logistics report 2006, http://www.eyefortransport.com/channel/logistics,2006-03-21

[3] Parasuraman, Zeithaml, and Berry (1985a, b), A conceptual model of service quality and its implications

for future research, Journal of marketing, Vol,49.\{Fall 1985\},41-50

[4] Parasuraman, Zeithaml, and Berry, Servqual: A multiple-Item scale for Measuring consumer perception of service quality, Marketing Science Institute, Cambridge, MA. Volume 64 Number 1, spring 1988

[5] Kim, JJ., Cheong, KJ., \& cho, g. Evaluating the service quality of third party logistics service providers Using The Analytic Hierarchy Process, Journal Of Information Systems And Technology Management Vol. 3, No. 3, 2006, P. 261-270issn Online: 1807-1775

[6] Tsaur, Chang, and Chang ,The Evaluation Of Airline Service Quality By Fuzzy Mcdm, Tourism Management 23 (2002) 107-115

[7] Jian C.Y, the Comparison And Reference For The Customer Satisfaction Index Model,

Http://Www.Lwlm.Com/Html/2008-09/138159.Htm,2008-09-07, , (In Chinese)

[8] Hair, J. F., Anderson, R. E., Tatham, R. L., And Black, W. C. Multivariate Data Analysis,5th Edition. Pearson Education, India, 2003.

[9] Gefen, D., Straub, D. W., And Boudreau, M. C. Structural Equation Modeling And Regression: Guidelines For Research Practice. Communications Of The Association for Information Systems, 6, Article 7, 2000, 1-30.

[10] Jewson, R. E-Payments: Credit Cards On The Internet, White Paper, 2001, 1-7.Available At <Www.Aconite.Net>. Accessed January 04, 2009.

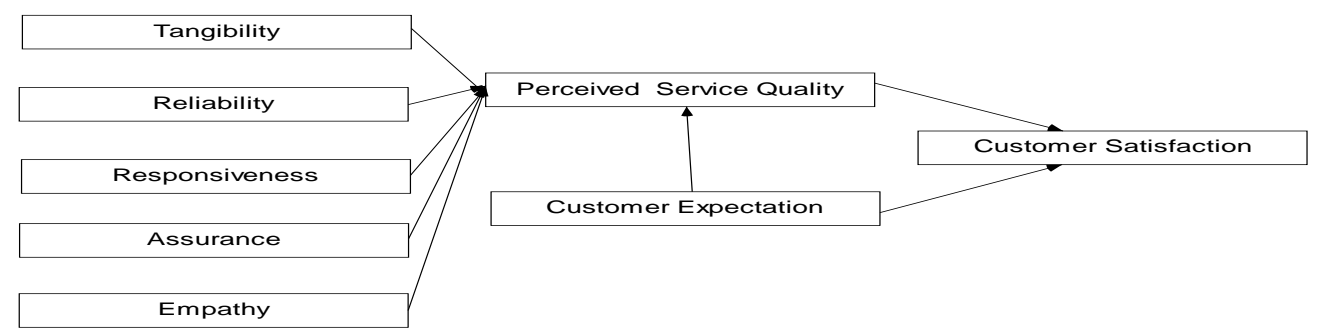

Fig 1 Customers' Satisfaction Model for third-party logistics service 